\title{
Modification of building energy simulation tool TRNSYS for modelling nonlinear heat and moisture transfer phenomena by TRNSYS/MATLAB integration
}

\author{
Ajaya Ketan Nayak ${ }^{1,2^{*}}$, Aya Hagishimal \\ ${ }^{1}$ Department of Energy and Environmental Engineering, Interdisciplinary Graduate School of Engineering Sciences, \\ Kyushu University, 6-1 Kasuga Koen, Kasuga, Fukuoka 816-8580, Japan \\ ${ }^{2}$ School of Mechanical Engineering, Kalinga Institute of Industrial Technology, Bhubaneswar 751024, Odisha, India
}

\begin{abstract}
Software for numerical simulation of various types of energy used in buildings, i.e. building energy simulation (BES), have become an essential tool for recent research pertaining to building physics. TRNSYS is a well-known BES used in both academia and the construction industry for a wide range of simulations, such as the design and performance evaluation of buildings and related facilities for heating, cooling, and ventilation. TRNSYS has a modular structure comprising various components, and each component is interconnected and compiled through a common interface using a FORTRAN compiler. Its modular structure enables interactions with various external numerical simulation tools, such as MATLAB, Python, and ESP-r. For ordinary simulations of building energy load using TRNSYS, the generic module Type 56 is usually recommended, which provides detailed physics modelling of building thermal behaviours based on unsteady energy conservation equations and Fourier's law for each building material. However, Type 56 explicitly depends on the transfer function method to discretise the original differential equations; therefore, it cannot model nonlinear phenomena, such as latent heat and moisture transfer between a building surface and ambient air. In other words, the current TRNSYS cannot be used to estimate the effectiveness of evaporation during cooling, which is a typical passive design method. Hence, the authors developed a MATLAB/TRNSYS integration scheme, in which TRNSYS was modified to model simultaneous heat and moisture transfer from the wet roof surface of a building. This scheme enabled TRNSYS to calculate the rate of evaporative heat and moisture transfer dynamically from the roof surface, assuming a control volume approximation of the roof surface. Finally, the effect of evaporative cooling on the thermal performance of an Indian building was estimated using the modified model.
\end{abstract}

\section{Introduction}

In recent years, several building energy simulation (BES) tools have become popular for evaluating the energy performance of new and existing buildings along with the increasing importance of energy saving and emission reduction in the building sector. In general, BES describes building thermal behaviours, enables the estimation of heating and cooling loads, indoor thermal climate, solar gains, and air infiltration rate; hence, it can be used for the design of heating, ventilation, and airconditioning (HVAC) systems [1-3]. TRNSYS is one of these BES tools, which is well known for its numerous validation studies and ability to model buildings incorporated with other systems, such as HVAC and renewable energy sources [4,5]. It has a modular structure that enables it to interact with various external numerical simulation tools, such as MATLAB, Python, and ESP-r [6].

TRNSYS employs the conduction transfer function (CTF) method developed by Mitalas and Stephenson to calculate transient heat conduction through slabs [7]. It involves the determination of transfer functions for one- dimensional heat transfer through building components by solving conduction equations using Laplace and $\mathrm{Z}$ transform theories [8]. However, the current implementation of the CTF in TRNSYS multizone building models, known as Type 56, cannot simultaneously analyse heat and moisture transport through building components. Type 56 has no specified module to handle the moisture content inside building walls or roofs.

Nevertheless, moisture transport through building envelopes is important for building hygrothermal performance, which affects mould-growth-related problems. Furthermore, the appropriate modelling of moisture transfer and the dynamic variation of moisture content of building envelopes are essential for the analysis of passive evaporative cooling.

Evaporative cooling by spraying water over roof surface is a well-known passive cooling technique widely used to reduce cooling loads in hot and dry climates in tropical and subtropical regions [9]. Various experimental and numerical studies have been performed to evaluate the effectiveness of roof spray evaporative

* Corresponding author: ajaya.ketana $@$ gmail.com 
cooling systems [10-11]. Furthermore, combined heat and moisture transfer models have been proposed to quantify the effect of evaporation from wet roof surfaces [12-13]. However, the integration of these models with building energy simulation tools is rare owing to various difficulties, such as complexity of existing software packages, difference in time step to model heat and moisture transport, nonlinearity in modelling, and numerical convergence.

Purohit et al. [14] were the first to model roof surface evaporative cooling using TRNSYS. However, simplification was adopted in their modelling, in which the saturation vapour pressure of water was assumed as a linear function of temperature within a narrow temperature range. In addition, the effective heat and transfer coefficients and effective temperatures (combining both convective and evaporative heat transfer) were calculated separately and fed to TRNSYS as the underside heat transfer coefficient and roof temperature, respectively. Although this approach provides a method to analyse evaporative cooling using TRNSYS, it does not consider the effect of moisture dynamics of the roof materials. Furthermore, validation based on experimental or numerical results has not been reported. Spanaky et al. [15] investigated the passive cooling effect of a ventilated roof pond protected with a reflecting layer and presented its numerical modelling using TRNSYS. They utilised module Type $344 \mathrm{~b}$ in TRNSYS, which was originally designed for outdoor swimming pools, and modified it to simulate a roof pond using Type 67. Their modelling presented good agreement with experimental data However, this approach cannot be directly applied for the modelling of evaporation from a wet roof or a roof with intermittent water spray.

Hence, the authors developed a component that enables the hygrothermal behaviour of a wet roof to be simulated by communicating with module Type 56 and the interaction with the entire simulation of a building model in TRNSYS. Herein, the roof surface evaporative cooling model is first presented briefly. In the subsequent section, the methodology that enables this model to interact with Type 56 is discussed with the associated complexities and assumptions. Next, the model was tested for a building with dry roof conditions, and the results were compared with the simulation results obtained for the same building using TRNSYS. Finally, the evaporative cooling effect reproduced by this model under the climatic condition of New Delhi, India are presented.

\section{Modelling of Roof surface evaporative cooling}

Previously, the authors have developed a simplified numerical model to estimate the cooling effect produced by transient evaporation from asphalt sheet roofing after a water spray considering the time variation of moisture content within a thin surface layer of roofs [17]. The mechanism can be explained as follows. The evaporation rate can be expressed as a function of water content of a roof surface layer. The water content is dependent on the amount of sprayed water and the subsequent evaporation. Hence, a water balance equation can be established for the surface layer and coupled dynamically with the heat conductive equation. The water balance equation and the evaporation rate are expressed by Equations 1 and 2, respectively.

$$
\begin{gathered}
\frac{\partial \phi}{\partial t}=P r-E V \\
E V=\beta\left(\frac{\emptyset}{\phi_{\text {max }}}\right) \cdot \frac{h}{c_{p m i} \cdot L_{W}} \cdot\left(X_{\text {sat }}\left(T_{\text {sur }}\right)-X_{\text {air }}\right)
\end{gathered}
$$

The heat transfer through the roof after a water spray is modelled using a one-dimensional unsteady heat transfer equation [18], as shown in Equation 3. The conduction, convection, and evaporative heat loss from the top surface of the roof are described by Equations 4 9 .

$$
\begin{gathered}
\rho C_{p} \frac{\partial T}{\partial t}=\lambda \frac{\partial^{2} T}{\partial x^{2}} \quad[0<x<l] \\
-\left.\lambda \frac{\partial T}{\partial x}\right|_{x=0}=h\left(\left.T\right|_{x=0}-T_{a}\right)+Q^{*}-L \cdot E V \\
Q^{*}=\alpha I_{s w}+\varepsilon I_{s k v}-\varepsilon \sigma T_{x=0}{ }^{4} \\
I_{s k y}=\varepsilon_{s k v} \sigma T_{r}^{4} \\
\varepsilon_{s k y}=0.526+0.076 \sqrt{f} \\
K_{x}=\frac{h}{L_{w} \cdot P_{m a} \cdot C_{p m}} \\
C_{p m}=C_{p . d r y-a i r}+X_{a i r} \cdot C_{p . v a p o r}
\end{gathered}
$$

The convective heat transfer between the indoor surface of the roof and the room air can be expressed as show in Equation 10. The convective heat transfer coefficient of the indoor surface of a roof was maintained constant at $9.6 \mathrm{~W} / \mathrm{m}^{2} \mathrm{~K}$. The outside convective heat transfer coefficient was calculated using a regression equation that was developed previously by one of the authors [19] and shown as Equation 11.

$$
\begin{gathered}
-\left.\lambda \frac{\partial T}{\partial x}\right|_{x=l}=h_{\mathrm{i}}\left(\left.T\right|_{x=l}-T_{r}\right) \\
h=2.14 \mathrm{v}+8.5
\end{gathered}
$$

More detailed information regarding the numerical model and the associated parameters are available in a previous study by the authors [17].

\section{Integration of Evaporative cooling model with TRNSYS}

\subsection{TRNSYS Architecture}


TRNSYS is the acronym for transient system simulation, a simulation programme primarily used in renewable energy and building simulation for passive and active solar designs [20]. It comprises a graphical user interface called Simulation Studio, which is a simulation kernel, and various component modules called 'Type'. A simulation project was formulated by interconnecting a set of component modules, such as solar collector, pump, and multizone building in a definite manner to represent the actual physical phenomena and then saved as a project definition file or 'deck' file. Subsequently, the simulation kernel accessed this deck file, performed an unsteady simulation, and created the desired outputs. The simulation was performed iteratively by the built-in solvers embedded in the kernel using a fixed time step until convergence was attained.

The modularity of TRNSYS provides flexibility for adding external components modelled with different tools, such as MS Excel, Python, R, and MATLAB. The Type 155 module establishes a link between MATLAB and TRNSYS. It enables TRNSYS to communicate with the MATLAB Engine through a component object model interface. Type 155 has two different calling modes: (i) standard iterative component, and (ii) realtime controller. In the first mode, MATLAB is invoked at each call of each time step, whereas in the second mode, it is referred at the first call of each time step with the converged inputs from the previous time step. In the scheme we developed, this feature was used to model heat and moisture transfer from a wet roof using TRNSYS. The evaporation from a wet roof surface was modelled in MATLAB using the previously described numerical model and integrated with multizone building component Type 56 using Type 155.

\subsection{Implementation in TRNSYS}

Although Type 155 enables to external MATLAB components to be called from TRNSYS, many problems are involved in the design principle of the integrated environment, such as the compatibility of the MATLAB component, time step, and parameter settings.

In this study, we used a procedure similar to those of Type 399 of Nostand [21] and 'slab on grade' type [22] in the TESS library. Figs. 1-3 illustrate the principle of integration between the wet roof component in MATLAB and the multizone building in TRNSYS. It can be summarised as follows:

i. The wet roof was modelled in MATLAB with all the required thermophysical parameters.

ii. The inputs to the wet roof component were as follows: solar heat flux (short wave radiation), wind velocity, atmospheric pressure, relative humidity, dry bulb temperature, and amount of water spray. iii. The desired building to assess the effect of evaporative cooling was designed with Type 56.

iv. The roof of the building in Type 56 was designed as a dummy roof with high thermal conductivity and low back side heat transfer coefficient $\left(\mathrm{H}_{\text {back }}<0.001\right)$ [22] to ensure a direct contact with the wet roof designed in MATLAB .

v. The temperature of the underside surface of a wet roof calculated using MATLAB was used as the boundary temperature for the dummy roof.

vi. The indoor air temperature and the heat gain of shortwave radiation absorbed through the wall of Type 56 building was used as an input to the MATLAB wet roof.

\subsection{Numerical Method}

The governing equations of heat and moisture transfer through a wet roof expressed by Equations 1 to 11 cannot be solved algebraically because of their nonlinearity. Hence, the control volume method was used for space discretisation and the finite difference method time discretisation. It is noteworthy that, to integrate the wet roof modelled in MATLAB with Type 56 of TRNSYS, the time step of both the simulations must be same. However, suitable time steps must be selected by considering the following:

i. Similar to other BES tools, TRNSYS is generally designed to perform annual energy load calculations with a time step of $1 \mathrm{~h}$. A short time step of less than 15 min usually imposes limitations on TRNSYS simulations

ii. To solve the problem of heat and moisture transfer through wet roofs numerically using MATLAB, the time step must be as small as possible. Large time steps such as $1 \mathrm{~h}$ results in unstable solutions.

iii. CTFs used by Type 56 are discrete time series equations, and the selected time steps are referred to as the time base to distinguish it from the main simulation time step. TRNSYS simulation can execute only if the simulation time step is less than or equal to the Type 56 time base.

iv. When the time base is greater than the time step, Type 56 interpolates the results of the CTF for the time steps. Therefore, for better simulation results, the ratio between the time step and time base should be as large as possible. In other words, for 
small simulation time steps, the value time base should be maintained low.

v. The lower the time base, the more coefficients are required to generate the transfer function equations. Therefore, a practical limitation is imposed on the selection of the lowest possible value for the time base for the problem under consideration.

vi. As a requirement, the Type 56 time base must be an integral multiple of the simulation time step.

For the given problem, the lowest possible value of the Type 56 wall time base is $1 \mathrm{~h}$, below which TRNSYS cannot generate transfer function coefficients. Hence, the time base was maintained as $1 \mathrm{~h}$, and the simulation time step was selected as $36 \mathrm{~s}$ or $0.01 \mathrm{~h}$ (ratio of time base to time step was 100) after several trial and error.

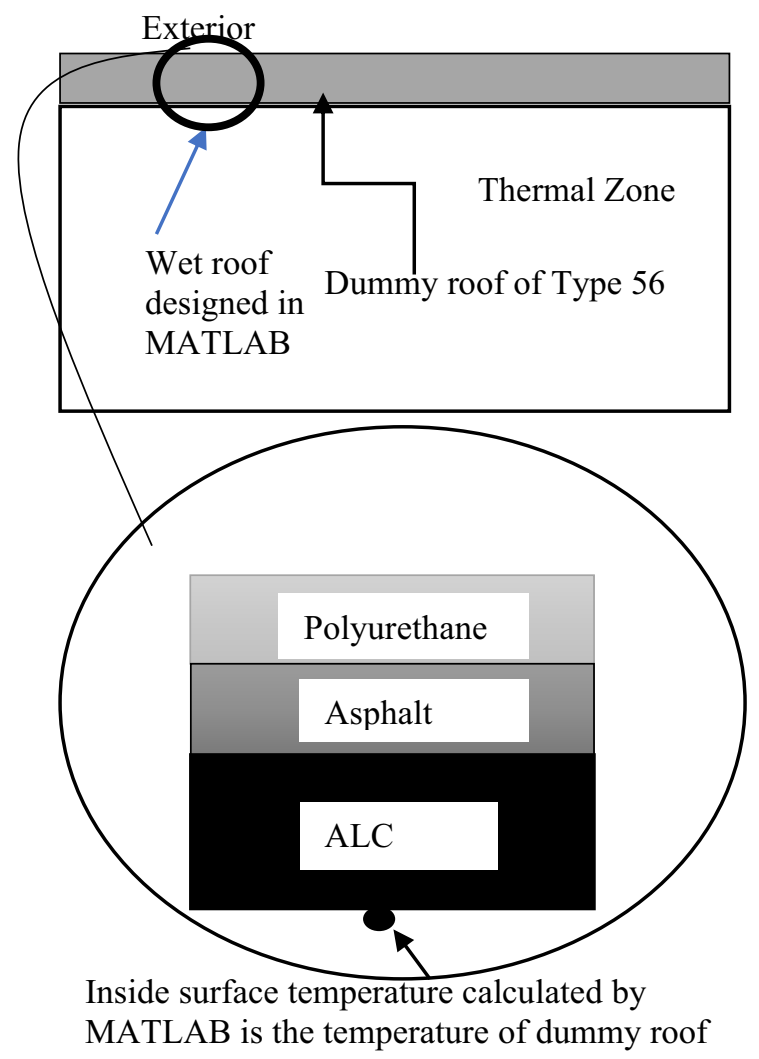

Fig. 1. Integration of MATLAB wet roof with Type 56

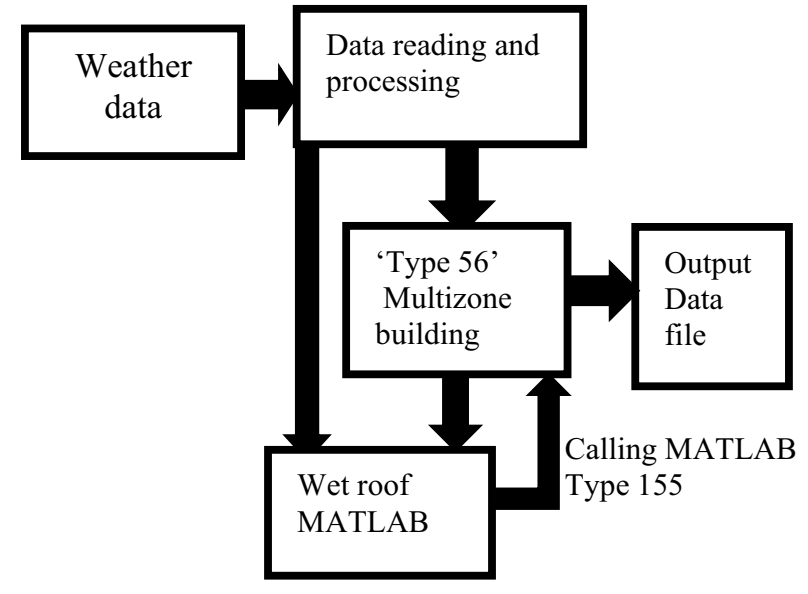

Fig. 2. TRNSYS flow diagram with MATLAB component

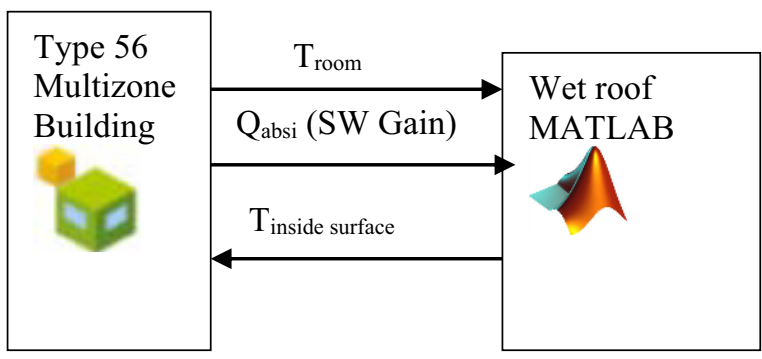

Fig. 3. Coupling MATLAB with TRNSYS Type 56

\section{Performance test of developed TRNSYS-MATLAB integration for dry roof condition}

The performance of the developed integrated module was tested by comparing the original TRNSYS model with the default Type 56 for a dry roof condition.

The simulation was performed for a single-room building. The building structure and thermophysical properties of the building materials are described in Table 1. Typical Meteorological Year (TMY) weather data of New Delhi, India $\left(28.6139^{\circ} \mathrm{N}, 77.2090^{\circ} \mathrm{E}\right)$ for 6 $\mathrm{d}$ from $1^{\text {st }}$ to $6^{\text {th }}$ May were used for the boundary conditions, and the simulation results of the period from $3^{\text {rd }}$ to $6^{\text {th }}$ May were used for analysis to avoid the effects of the initial conditions. Fig. 4 depicts the hourly variations of solar radiation, relative humidity, ambient temperature, and wind speed. As the weather data were available at $1 \mathrm{~h}$ intervals, linear interpolation was employed to generate weather changes at each $36 \mathrm{~s}$ interval and used as input for the numerical simulations. The combined convective and radiative heat transfer coefficient for the inside surface of the building was assumed to be $9.6 \mathrm{~W} / \mathrm{m}^{2} \mathrm{~K}$. The target building was assumed as ventilated with an air infiltration rate of 0.6 $/ \mathrm{h}$ and no internal heat gain/sink. 

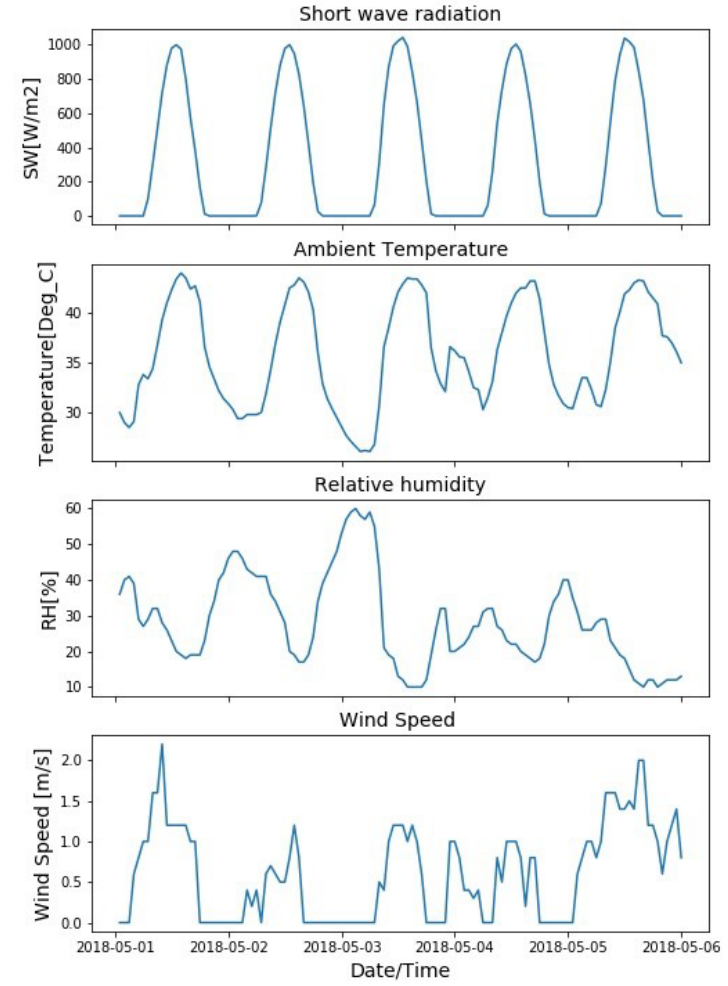

Fig. 4. Weather data of New Delhi, India from $1^{\text {st }}$ to $6^{\text {th }}$ May used for analysis of dry roof

Fig. 5 compares the room air temperatures obtained using the original TRNSYS and the newly developed model with MATLAB integration. The temperatures of the outside and inside surfaces of the roof for both cases are included. As shown in the bottom plot, the outside surface temperatures of the roof for both simulations are similar except from 2:00 am to 7:00 am on $4^{\text {th }}$ May. During this period,

the difference between the roof top surface temperature obtained from the TRNSYS-only model and the integration model is relatively high with a maximum amplitude of $2.3{ }^{\circ} \mathrm{C}$. The middle plot compares the inside surface temperature of both cases. They match closely with each other with a maximum difference of only $1.4{ }^{\circ} \mathrm{C}$ from 9:00 am to 12:00 pm on 3rd May.

Finally, the indoor air temperature of both models are compared in the top plot. The difference between the TRNSYS and TRNSYS-MATLAB integration models varied in a nearly cyclic manner from $-1.2{ }^{\circ} \mathrm{C}$ to $2.1{ }^{\circ} \mathrm{C}$. The mean absolute deviations in temperature of the room air, roof top, and bottom surface were calculated to be $0.3{ }^{\circ} \mathrm{C}, 0.7{ }^{\circ} \mathrm{C}$, and $0.5{ }^{\circ} \mathrm{C}$, respectively. This analysis proves that the new integrated model equipped with a roof modelled in MATLAB can successfully predict the thermal behaviour of a dry roof with minimal error. The discrepancy may be attributed to the lower time step selected for TRNSYS simulation, assumed values of material properties, and convective heat transfer coefficient. Therefore, this model can be used to analyse the heat transfer through a wet roof, which is otherwise impossible in TRNSYS.
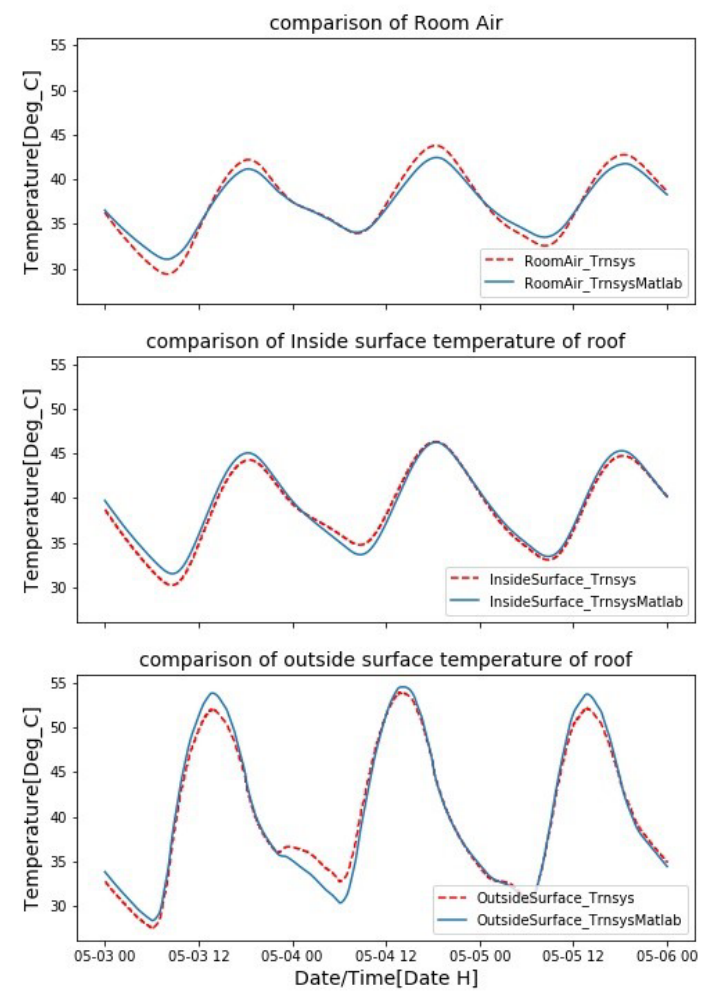

Fig. 5. Comparison of simulation result of TRNSYS and TRNSYS MATLAB for New Delhi, India from 1st to 6th May

\section{Case study of roof surface evaporative cooling using modified TRNSYS tool.}

To assess the effect of evaporative cooling by spraying water over the roof, a single-room building with a roof structure, as shown in Fig. 6, was selected as a case study. It was assumed that water was sprayed twice daily at 7:00 am and 12:00 pm at a uniform rate of $1 / 6 \mathrm{~kg} / \mathrm{min}$ for $30 \mathrm{~min}$. Considering the physical structure of the roof, the following assumptions were made for the numerical modelling: (i) no internal heat is generated within any material layer, (ii) each layer is homogenous with constant thermophysical properties, (iii) an appropriate contact exists between layers with no interface resistance, (iv) the thermophysical properties of the roof material is independent of water content. The modified TRNSYS model was used to analyse the temperature distribution through the roof with and without water spray. The simulation was performed using TMY weather data of New Delhi, India with a time step of $36 \mathrm{~s}$. New Delhi is categorised as a composite climate zone that is extremely hot in the summer and severely cold in the winter. Generally, June is the hottest month, with the daily maximum temperature exceeding $40{ }^{\circ} \mathrm{C}$. Therefore, a hot and clear 
week in June (6th to 13th) with a daily maximum temperature exceeding $35^{\circ}$ and a relative humidity between $20 \%$ and $60 \%$ was selected for the analysis. Fig. 7 describes the weather data of that week. For a simple analysis, the simulation result for 8th June is discussed.

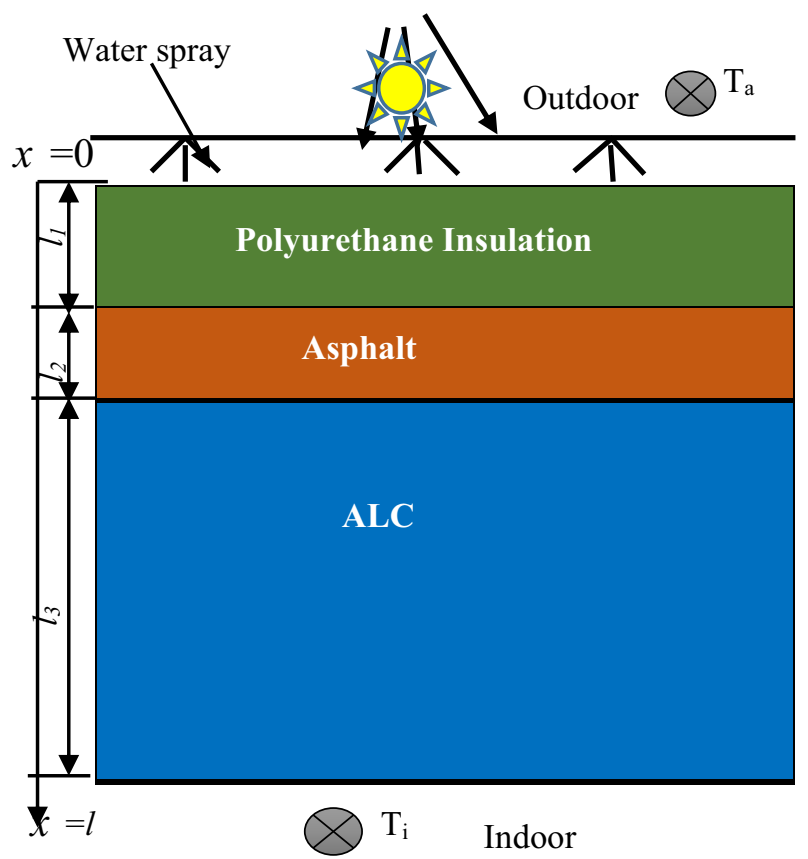

Fig. 6. Schematic representation of the wet roof selected for the case study

The effects of water spray on the indoor air temperature, moisture content of roof, and evaporative heat flux on $8^{\text {th }}$ June are depicted in Fig. 8. As shown from the graph depicting evaporative flux, evaporation begins immediately after the water spray at 7:00 am, reaches the maximum and then continues up to 10:00 am at a decreasing rate before diminishing to zero. Similar pattern of evaporation is seen after water spray at $12 \mathrm{pm}$. But, the amplitude of the maximum evaporative flux at $12 \mathrm{pm}$ is nearly four times that at $7 \mathrm{am}$. This is owing to the larger solar radiation and ambient temperature at noon compared with those in the morning. Furthermore, the effect of evaporation starting at 7:00 am remained for more than $2 \mathrm{~h}$, whereas that starting from 12:00 pm diminished in $1.5 \mathrm{~h}$. Owing to the high evaporation rate during noon time, the moisture content of the roof material decreased rapidly, resulting in a faster decrease in the evaporation flux. The maximum amount of evaporative flux was $2156 \mathrm{~W} / \mathrm{m}^{2}$ at 12:01 pm immediately after water spray.

From the plot of roof moisture content, it can be deduced that when water was sprayed over the roof, the moisture content increased rapidly and attained the maximum threshold value, which was $0.45 \mathrm{~kg} / \mathrm{m}^{2}$ for the roof material calculated in a previous study by the author [17]. Then as evaporation begins, the moisture content decreases and reduces to zero after a few hours. Comparing the plot of evaporative flux and moisture content, it can be inferred that, as the evaporation rate at
7:00 am is lower than that at $12 \mathrm{pm}$, the moisture content requires more time to diminish completely at 7:00 am than at a later time.
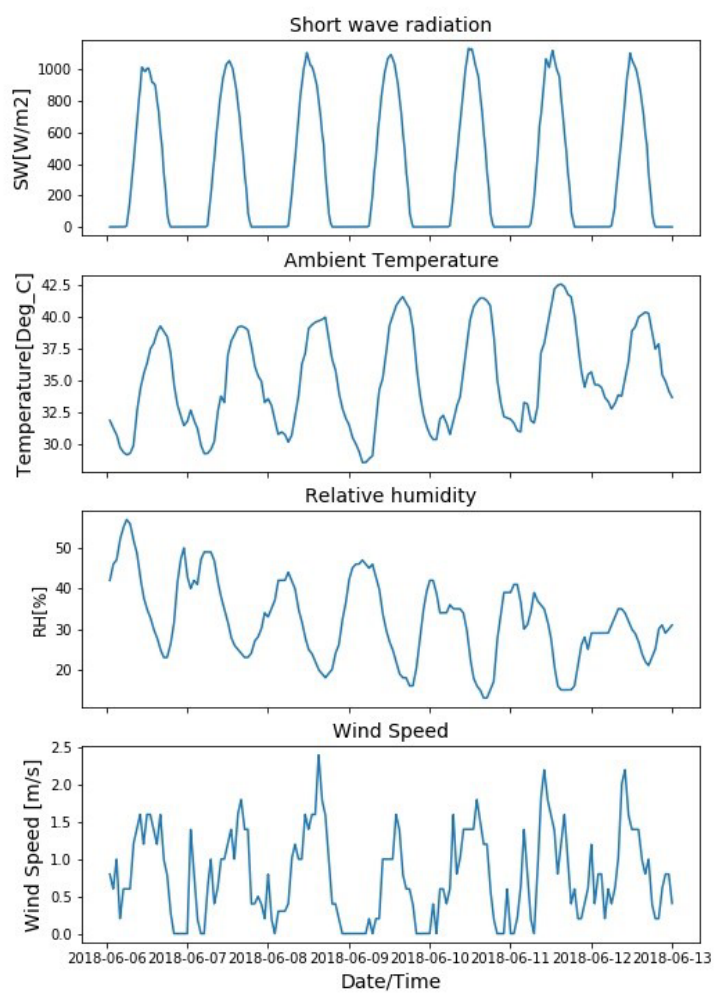

Fig. 7. Weather data of New Delhi, India from 6th to 13th June for simulation

The top plot shows the variation in outside surface temperature of the roof with and without employing evaporation cooling. As shown, before water was sprayed, the outside surface temperature of the roof for both cases were similar. However, as water was sprayed at $7 \mathrm{am}$, the corresponding roof temperature decreased. The decrease in roof temperature continued for approximately $2 \mathrm{~h}$ until the effect of evaporation cooling remained prevalent. When evaporation ceased, it again increased and immediately before water was sprayed again at 12:00 pm, it was approximately the temperature of the roof without employing evaporation. After the second water spray, the temperature of the outside roof surface decreased rapidly, and the difference between two roofs attained a maximum value of approximately $15{ }^{\circ} \mathrm{C}$ at 12:32 pm. As the effect of evaporation decreased, the temperature of the wet roof increased gradually and approached that of the dry roof after approximately $6 \mathrm{~h}$. Furthermore, the second water spray at 12:00 pm exerted a more pronounced effect on the roof top surface temperature in terms of maximum temperature drop and continuation of cooling effect than the first spray at 7:00 am. This was because the rate of 
evaporation was higher at noon time than that in the morning. Therefore, it can be concluded that the time of water spray significantly affects the effectiveness of evaporative cooling.

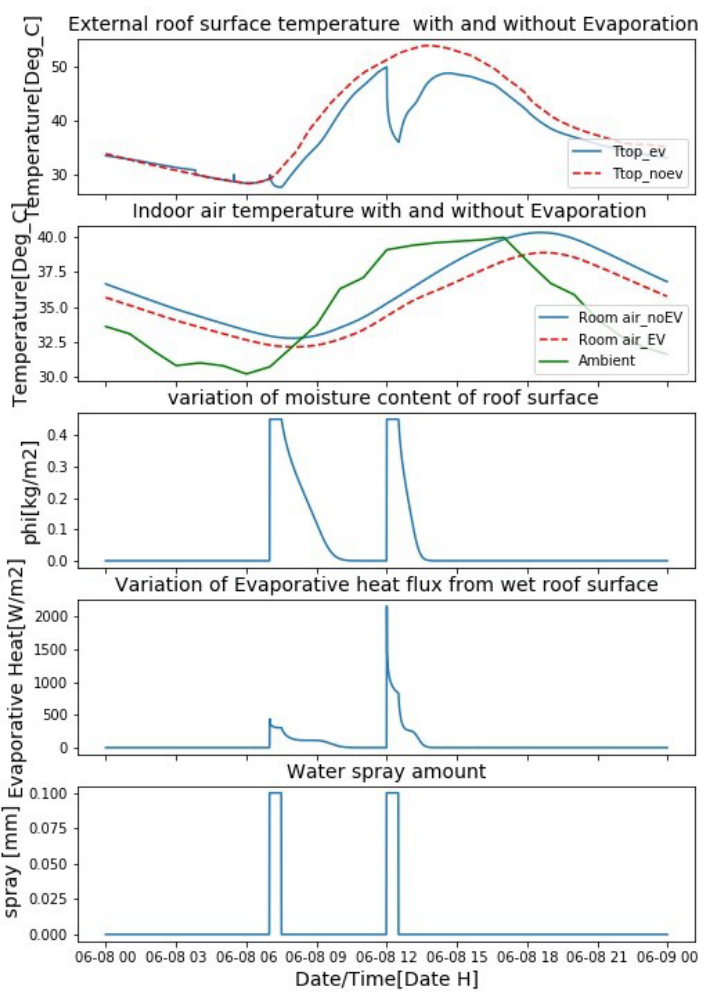

Fig. 8. Variations in evaporative flux, moisture content, and indoor air temperature with water spray on 8th June

The variation in indoor air temperature for both cases are shown in the second plot along with the ambient temperature. Unlike the roof top surface temperature, the difference in room air temperature of the building with and without evaporation remained nearly uniform. The maximum difference between the two was approximately $1.4{ }^{\circ} \mathrm{C}$ at $4 \mathrm{pm}$. This was because the room air temperature was strongly affected by the assumption of the roof-area-to-room-volume ratio and the thermal mass of the building roof and walls.

\section{Discussion and Conclusions}

The water content of building materials are important for the evaporative cooling of buildings. Hence, the dynamic variation of moisture content of roof materials must be considered for the numerical modelling of evaporation from the roof surface after water spray. However, the current version of TRNSYS cannot simultaneously model heat and moisture transport through building envelopes. Therefore, a modified tool was developed by integrating TRNSYS with MATLAB using the Type 155 module.

The integration of MATLAB with TRNSYS involves defining a dummy roof in TRNSYS with a low backside heat transfer coefficient such that a direct contact is established between the building designed with Type 56 and the wet roof modelled in MATLAB. The room temperature obtained from TRNSYS simulation was provided as an input to the MATLAB simulation, whereas the temperature of the inside surface of the wet roof modelled in MATLAB was considered as the temperature of the dummy roof of the building designed using TRNSYS. This strategy is consistent with the 'slab on grade' type [22] in the TESS library.

The numerical solution of simultaneous heat and moisture transfer equations by MATLAB requires a small-time step in the order of a few seconds. However, a small-time step requires a smaller time base, which presents some practical limitations in terms of the generation of wall transfer function coefficients. Hence, considering all the constraints, the time base was assumed to be $1 \mathrm{~h}$ and the time step was fixed at $36 \mathrm{~s}$.

The performance of the modified model was tested by comparing it with the original TRNSYS model for a dry roof condition without evaporation. The results of the modified model agreed well with that of TRNSYS with mean absolute deviations in temperature of only 0.3 ${ }^{\circ} \mathrm{C}, 0.7{ }^{\circ} \mathrm{C}$, and $0.5{ }^{\circ} \mathrm{C}$ for the room air, roof top, and roof bottom surface, respectively.

A single-room building located in the climatic condition of New Delhi, India was selected as a case study to analyse the effect of evaporative cooling by spraying water over a roof surface at a rate of $1 / 6 \mathrm{~kg} / \mathrm{min}$ for $30 \mathrm{~min}$ twice daily. The maximum decrease in external roof surface temperature owing to water spray at 12:00 pm on $8^{\text {th }}$ June was approximately $15^{\circ} \mathrm{C}$.

Even though this model can be used successfully to analyse the evaporation from the building roof after water spray, its accuracy still depends highly on the appropriate selection of time base and time step of the simulation. A lower time base value (less than one hour) will improve the accuracy, but an improved algorithm for CTF generation in Type 56 is required.

\section{Nomenclature}

\begin{tabular}{|c|c|}
\hline$C_{p}$ & Specific heat $\left[\mathrm{J} \mathrm{kg}^{-1} \mathrm{~K}^{-1}\right]$ \\
\hline$C_{p m}$ & Specific heat of moist air $\left[\mathrm{J} \mathrm{kg}^{-1} \mathrm{~K}^{-1}\right]$ \\
\hline$E V$ & Evaporation rate from roof $\left[\mathrm{kg} \mathrm{m}^{-2} \mathrm{~s}^{-1}\right]$ \\
\hline$h$ & $\begin{array}{l}\text { Outside convective heat transfer coefficient } \\
{\left[\mathrm{W} \mathrm{m}^{-2} \mathrm{~K}^{-1}\right]}\end{array}$ \\
\hline$h_{i}$ & Inside convective heat transfer coefficient \\
\hline$f$ & Water vapour pressure $[\mathrm{mm} \mathrm{Hg}]$ \\
\hline$I_{s k y}$ & Atmospheric radiation $\left[\mathrm{W} \mathrm{m}^{-2}\right]$ \\
\hline$I_{s w}$ & Shortwave radiation $\left[\mathrm{W} \mathrm{m}^{-2}\right]$ \\
\hline$K_{x}$ & $\begin{array}{l}\text { Mass transfer coefficient } \quad\left[\mathrm{kg} \mathrm{m}^{-2} \mathrm{~s}^{-1}\left(\mathrm{~kg} \mathrm{~kg}^{\prime}\right.\right. \\
\left.\left.{ }^{1}\right)^{-1}\right]\end{array}$ \\
\hline$L$ & Latent heat of vaporisation of water $\left[\mathrm{J} \mathrm{kg}^{-1}\right]$ \\
\hline$l$ & Roof thickness [m] \\
\hline$L_{w}$ & Lewis number [-] \\
\hline$Q^{*}$ & Net radiation heat transfer $\left[\mathrm{W} \mathrm{m}^{-2}\right]$ \\
\hline$T$ & Temperature of roof surface $[\mathrm{K}]$ \\
\hline
\end{tabular}




\begin{tabular}{|c|c|}
\hline$T_{\text {air }}$ & Temperature of ambient air [K] \\
\hline$T_{\text {sur }}$ & Temperature of external roof surface $[\mathrm{K}]$ \\
\hline$T r$ & Temperature of external roof surface $[\mathrm{K}]$ \\
\hline$v$ & Wind velocity $\left[\mathrm{m} \mathrm{s}^{-1}\right]$ \\
\hline $\mathrm{x}$ & Position coordinate, vertically down [m] \\
\hline$X_{\text {sat }}\left(T_{s}\right)$ & Saturated absolute humidity at $\mathrm{T}_{\text {sur }}\left[\mathrm{kg} \mathrm{kg}^{\prime-1}\right]$ \\
\hline$X_{\text {air }}$ & Absolute humidity of outside air [ $\left.\mathrm{kg} \mathrm{kg}^{9-1}\right]$ \\
\hline$\varepsilon$ & Emissivity [-] \\
\hline$\alpha$ & Absorptivity [-] \\
\hline$\rho$ & Density $\left[\mathrm{kg} \mathrm{m}^{-3}\right]$ \\
\hline$\lambda$ & Thermal conductivity $\left[\mathrm{W} \mathrm{m}^{-1} \mathrm{~K}^{-1}\right]$ \\
\hline$\sigma$ & Stefan-Boltzmann constant $\left[\mathrm{W} \mathrm{m}^{-2} \mathrm{~K}^{-4}\right]$ \\
\hline$\phi$ & Surface water content $\left[\mathrm{kg} \mathrm{m}^{-2}\right]$ \\
\hline$\phi_{\max }$ & Maximum water content of surface $\left[\mathrm{kg} \mathrm{m}^{-2}\right]$ \\
\hline
\end{tabular}

\section{References}

1. F. Fermanel, Air heating system: influence of a humidifier on thermal comfort, Applied Thermal Engineering 19, 1107-1127(1999).

2. H. Ben Cheikh, Passive cooling by evaporeflective roof for hot dry climates, Renewable Energy 29, 1877-1886(2004).

3. X. Lu, T. Lu, A new analytical method to simulate heat transfer process in buildings, Applied Thermal Engineering 26, 1901-1909(2006).

4. D.B. Crawley, J.W. Hand, contrasting the capabilities of building energy performance simulation programs, Building and Environment 43(4), 661-673(2008)

5 TRNSYS 17 - A Transient System Simulation Program, https://qcd.co.jp/down/SHEET/T17Updates.pdf

6 M. Ibanez, An approach to the simulation of PCMs in building applications using TRNSYS, Applied Thermal Engineering 25(11-12), 17961807(2005).

7 Stephenson D.G., Mitalas G.P., Calculation of heat conduction transfer functions for multi-layer slabs,ASHRAE Transactions, 77(2), 117-126, 1971.

8 TRANSSOLAR Energietechnik GmbH, Solar Energy Laboratory, TRNSYS 17

9 G.N. Tiwari, A. Kumar, M.S. Sodha, A reviewcooling by water evaporation over roof, Energy Convers. Manage. 22 (1982) 143-153.

10 M.M. Shah, Rate of evaporation from undisturbed water pools: evaluation of available correlations, Int. J. HVAC\&R Res. 8 (2002) 125-132.

11 G.H. dos Santos, N. Mendes, Numerical analysis of passive cooling using a porous sandy roof, Applied Thermal Engineering 51 (1) (2013) 25-31.

12 W. Chen, Thermal analysis on the cooling performance of a wet porous evaporative plate for building, Energy Conversion Management. 52, 2217-2226(2011).

13 M Hendel, An analysis of pavement heat flux to optimize the water efficiency of a pavementwatering method, Applied Thermal Engineering 78, 658-669(2015).
14 I. Purohit, Thermal simulation of roof surface evaporative cooling system for India using "TRNSYS", International Journal of Ambient Energy 27(4), 193-202(2006)

15 A. Spanaki, Assessing the passive cooling effect of the ventilated pond protected with a reflecting layer, Applied Energy 123, 273-280(2014).

16 K.T. Zingre, Modelling of cool roof performance for double-skin roofs in tropical climate ,Energy 82, 813-826(2015).

17 A. Nayak, A. Hagishima, A simplified numerical model for evaporative cooling by water spray over roof surfaces, Applied Thermal Engineering 165, $114514(2020)$

18 Ö. Kas, Energy Comparison of experimental and theoretical results for the transient heat flow through multilayer walls and flat roofs,33(12), 1816-1823(2008)

19 H. Aya, T. Jun, Field measurements for estimating the convective heat transfer coefficient at building surfaces, Build. Environ. 38 (2003) 873-881.

20 B. Delcroix1, conduction transfer functions in trnsys multizone buildingModel: current implementation, limitations and possible Improvements IBPSA-USA (2012)

21 TRNSYS 18 Documentation, Nostand, Type 399(2004).

22 S.A. Klein, et al., TRNSYS 16(2004). 